\title{
Mineral associated organic matter and soil health in Hawaii
}

\author{
Christine TAllamy GlaZer ${ }^{1}$, SUSAN E. CROW ${ }^{1}$, \\ HANNAH HUBANKS ${ }^{1}$, M. FRANCESCA COTRUFO ${ }^{2}$, \\ MICHELLE HADDIX ${ }^{2}$ \\ ${ }^{1}$ University of Hawaii Manoa, Honolulu, HI, USA \\ (ctg@hawaii.edu,crows@hawaii.edu, \\ hhubanks@hawaii.edu) \\ ${ }^{2}$ Colorado State University, Ft. Collins, CO, USA \\ (Francesca.Cotrufo@colostate.edu, \\ michelle.haddix@colostate.edu)
}

Soil organic matter (SOM) is a critical factor in soil health and fertility, which encompasses biological, chemical, and physical soil parameters that holistically represent soil ecosystem function. We characterized 22 sites across broad natural and working lands and soil types in Hawaii for 46 soil health parameters. Land use was the predominant factor influencing soil health, but broad mineralogical classifications were also important determinants (Figure).

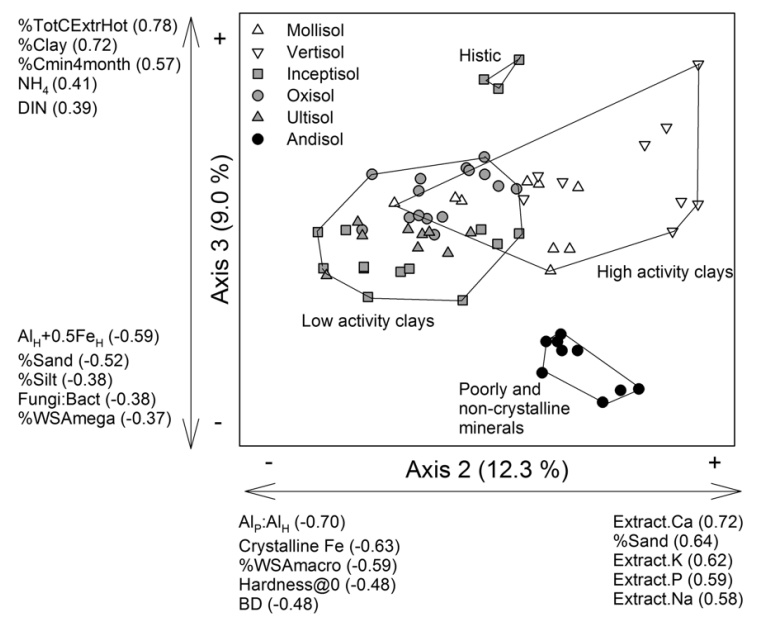

We physically fractionated soils into four pools: dissolved organic matter, light and heavy particulate organic matter (LPOM and HPOM), and mineral associated organic matter (MAOM). Whereas a greater percentage of LPOM and HPOM were found in the histic and poorly and noncrystalline mineral soils, greater percentages of the soil was in the MAOM fraction in the high and low activity clay soils. All forms of SOM contribute to soil health: POM is critical for soil fertility, structure, and water retention; but MAOM is more persistent and contributes to sequestration. Partitioning among fractions differed for broad mineral classifications. 